\title{
Enhancing The Effectiveness Of HR Through The Integration Of IT
}

Sunil J. Ramlall (E-mail: sjramlall@stthomas.edu), University of St. Thomas

\begin{abstract}
There is little doubt that technology is reshaping the way business in conducted in today's society. The goal of a business remains as an organized effort of individuals to produce and sell, for a profit, products and services that satisfy society's needs, but with greater utilization of technology to effectively compete in the global economy. Given the shift, this paper examines the relationship between Human Resource (HR) and Information Technology (IT) and their convergence in creating and sustaining competitive advantages. The paper addresses the major aspects of the HR function and how IT can be integrated in creating value for the organization.
\end{abstract}

\section{Introduction}

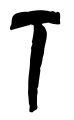

here is little doubt that technology is reshaping the way business in conducted in today's society. Historically, business could have been defined as the organized effort of individuals to produce and sell, for a profit, products and services that satisfy society's needs (Canzer, 2003). Today, the goal is the same, but with greater utilization of technology to "fend off competitors, reinforce an existing competitive advantage, leapfrog competitors, or just make money in new markets" (Afuah \& Tucci, 2003). Any company that isn't constantly developing, or adapting new technology will likely be out of business in a few years (Daft, 2001). Given the shift in societal norms, this paper examines the relationship between Human Resource (HR) and Information Technology (IT) and their convergence in creating and sustaining competitive advantages.

A major study of HR in large organizations conducted by the Human Resource Planning Society and the Center for Effective Organizations (CEO) study of HR in large corporations concluded that there is a critical need for organizational leaders to focus on the development of a business partner relationship and the use of information technology to help increase profitability (Lawler \& Mohrman., 2000). To support the call for more of an integration between HR and IT, Coates (2001) stated that in most firms, human resource (HR) departments are an underperforming and underdeveloped resource, and suggests that HR departments engage in strategic planning to create new opportunities including the integration of information technology. Furthermore, a study by the Society for Human Resource Management (2002) identified technology as the primary trend within the HR profession.

\section{Why is there a need for theoretical explanations in HR?}

As a relatively new discipline, there is still an imperative need for theoretical explanations to reduce the frequency of practices based on incomplete espoused theories and "gut feelings." Moreover, with theoretical explanations, HR professionals are more able and competent in understanding employees' behaviors in organizations, better prepared to influence practices and behaviors, and predict behaviors based on past practices.

Theory can be defined as the attempt to model some theoretical aspect of the real world with the purpose of making sense of the observable world by ordering the relationships among elements that constitute the theorist's focus of attention in the real world (Dubin, 1978). Toracco (1997) provided another definition of theory as an explanation of what a phenomenon is and how it works. As cited in Lynham (2000), Bacharach (1989) offered a

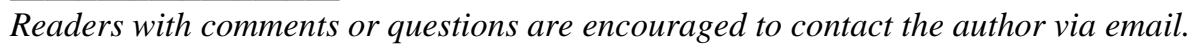


similar definition to that of Dubin, describing theory as a statement of relationships between units of observed or approximated in the real world.

With the growing use of technology in organizations to create and sustain competitive advantages, it is critical to understand the Relation between HR and IT, especially given one of HR's roles as advisors in helping other business leaders compete in the Web-based economy. Ulrich (2000) stated that HR professionals in the Webbased world need to become literate in Web-based technology to use it and create distinctive competence in how HR investment can be enhanced through technology. The need is strengthened given that in the future according to Ulrich, HR professionals will be at the intersection of three sets of skills: business strategy, HR mastery, and technology.

The need for theory in HR is echoed by Boudreau \& Ramstad (2002) stating that the historical lessons from finance and marketing suggest that the symptoms and challenges faced by HR today will not be addressed simply by continued incremental improvements. Rather, the authors articulate that the next critical step in the evolution of HR is a decision science approach. According to Boudreau \& Ramstad, "decision science provides a logical, reliable, and consistent - but flexible framework that enhances decisions about a key resource, wherever those decisions are made. A decision science does not rigidly prescribe what to do, but rather provides a logical system to identify and analyze key decision issues."

HR professionals are already using technology to some extent, but the question of whether it is being accepted, maximized, and measured still needs to be answered. There is the imperative need to understand how HR can incorporate IT in their strategy to attract and retain the individuals who will create the competitive advantages and have the processes that support the business strategy (Huselid, 1995). Recent examples among local and companies overseas have shown the importance of IT being integrated into HR practices to increase profitability. For example, Deutsche Bank has made its human resources component a strategic partner in its business by making each human resources person a change agent and defining strategic competency. Development and information technology were prime movers in changing Deutsche Bank's personnel management (Svoboda \& Schroder, 2001).

In the age of a Web-based economy, it would be most useful and beneficial for HR professionals to understand the Relation between HR \& IT and utilize a theoretical approach in enhancing the performance of the HR function through the integration of IT. Furthermore, the emergence of knowledge as the human resource management's key resource will certainly necessitate radically new management theories and practices including the area of information technology as a replacement of administrative tasks in organizations (Patra, Khatik, \& Kodwani, 2002).

\section{Strategic HR in the $21^{\text {st }}$ Century}

The human resource (HR) management function has evolved over the years from being mostly administrative to today's role as "Strategic Business Partners," "Players," and "Talent Leaders" in organizations. "The objective of HR professionals is to ensure that HR adds value to strategic planning and business results of the organization" (Ulrich, 2001). Similarly stated, the fundamental role of HRM is essentially to maximize profitability, quality of work life and profits through effective management of people (Cascio, 2003). Given this premise, it can be easily inferred that HR's role is to help create value for the organization.

Could HR integrate IT to enhance its value creation efforts? With the growing use of information technology in creating competitive advantages in organizations, HR's need to be competent in technology allowing HR practitioners to deal effectively with intranets, self-service, online recruiting, e-learning, online employee surveys, and other initiatives are quickly becoming a requirement. According to the Department of Commerce (2002), as of September 2001, almost 57\% of the 115 million employed workers age 25 years and older used a computer at work. Of those workers, $74 \%$ (48 million) also have Internet access. These data reflect a $26.7 \%$ as reported in 2000. 
Figure 1

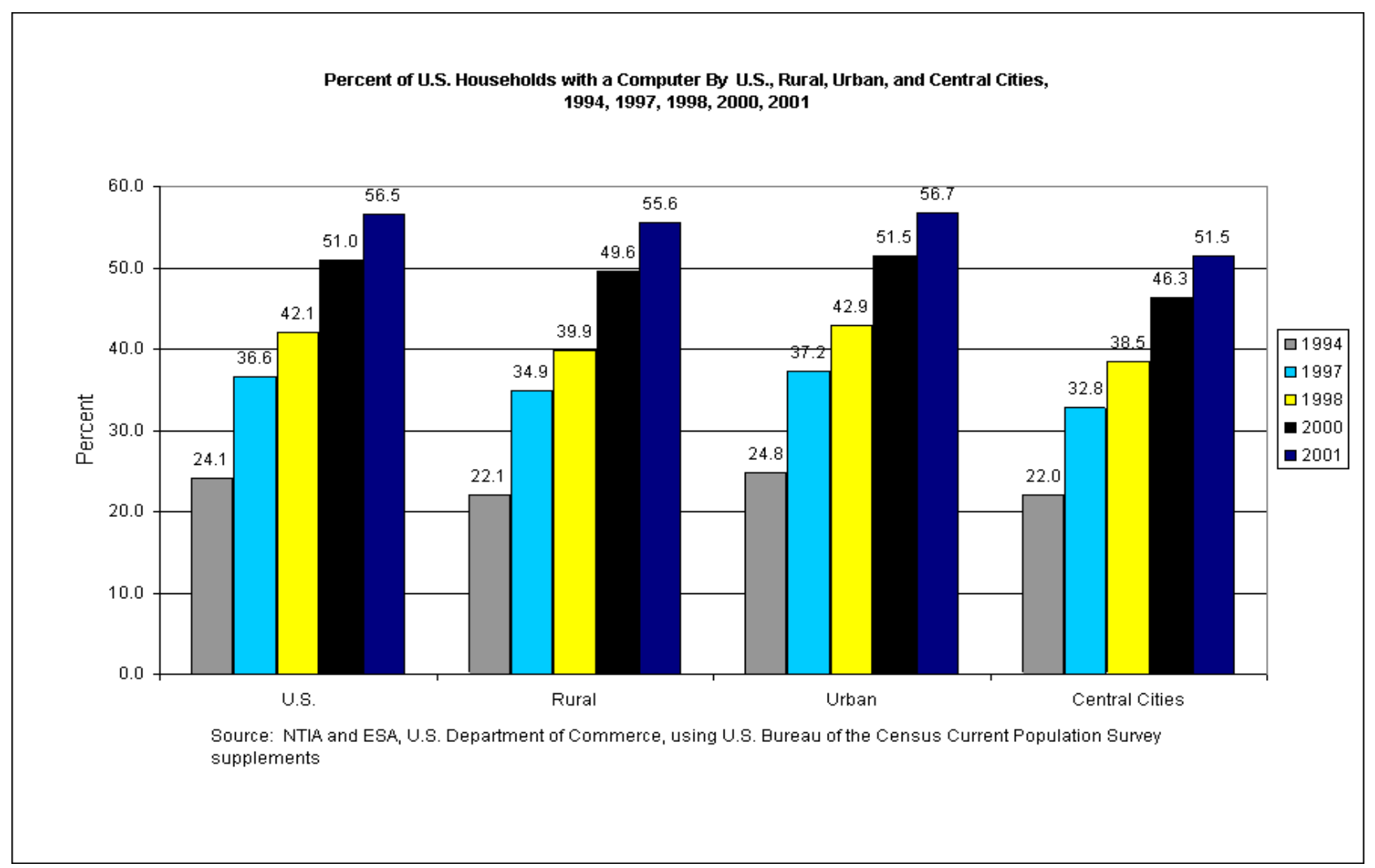

Given the significant increase in the use of computers and the Internet, the question of how HR's strategies are influenced by this change are addressed with specific emphasis on enhancing these strategies by the technology available.

\section{Technology as a Value Added Resource}

It can be argued that over the past decade IT has been one of the largest changes impacting organizations (Viere, 2003). Technology is changing the way we work, the roles we undertake, and the interactions through which work gets done (DeFillippi, 2002). Avgerou (2000) explained that within a period of thirty years, IT acquired the legitimacy of an "enabler" in organizations and became one of the most significant factors justifying and enacting organizational change (p.240). It has since become one of the most definitive characteristics of the global economy.

With a digital workplace that is built around employees with computers and Internet access (Benson, Johnson, \& Kuchinke, 2002), the intent is to enhance productivity of employees and overall organizational performance. The intended outcomes of IT include improvements in customer relationship management, business intelligence and decision support, enterprise resource planning, knowledge management, supply chain management, and e-commerce (Viere, 2003). Furthermore, virtually all IT endeavors are funded on the basis of a value generating performance improvement potential with the potential to a) reduce costs, and b) improve organizational effectiveness (Devaraj \& Kohli, 2000). 
Figure 2

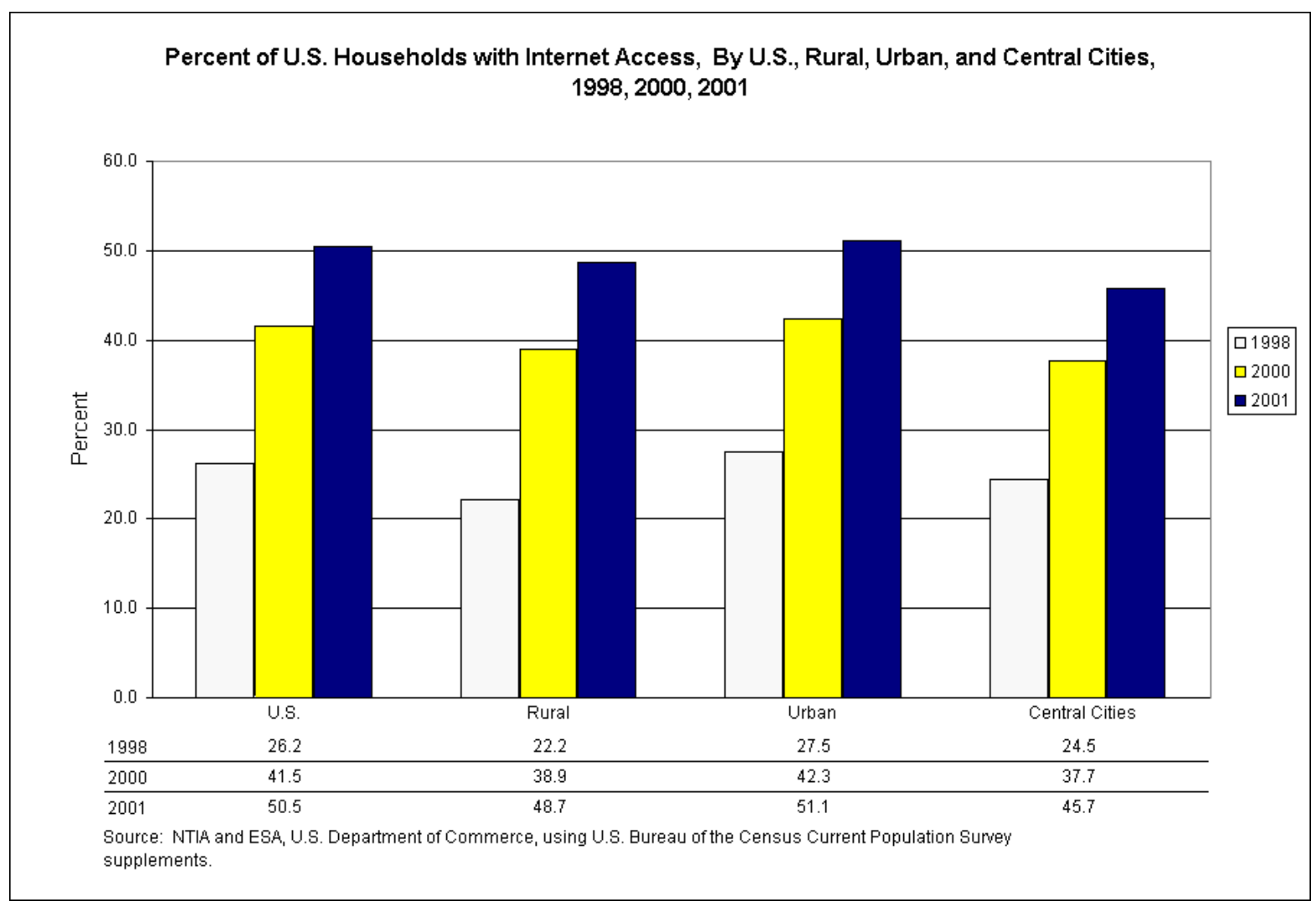

In recent years, companies such as Target Corporation, Walmart, Best Buy, etc. have revamped their ecommerce to the extent where revenue generated through such medium can be compared to a brick and mortar store. Utilizing available technology is a necessary component of any forward-thinking organization in the global economy.

The new economy is knowledge-based economy without borders, where the race is between companies and locales over how to learn faster and organize more flexibility to take advantage of the technology-enabled market opportunities (Kelly, 1998). It is in part through technology that companies have been able to compress time cycles for satisfying customer requirements and reducing costs. Furthermore, it is through technological advancements that companies have been able to collaborate with each other, contractors, and other stakeholders.

\section{Improving HR's Performance through the Integration of IT}

Given the respective purpose of HR and IT to create value, there are strong arguments that through collaboration between these two extremely critical components of a business, both IT's and HR's output can be enhanced resulting in higher levels of performance at the individual, department, and organization levels. In a model proposed by Ulrich (2000), HR provides IT with HR practices to ensure that IT has the talent, discipline, and accountability to design and use technology to provide decision based data. In addition, IT provides HR with technological infrastructure to more efficiently and effectively deliver HR. 
Figure 3: Systems Model Approach Showing the Relation between HR \& IT

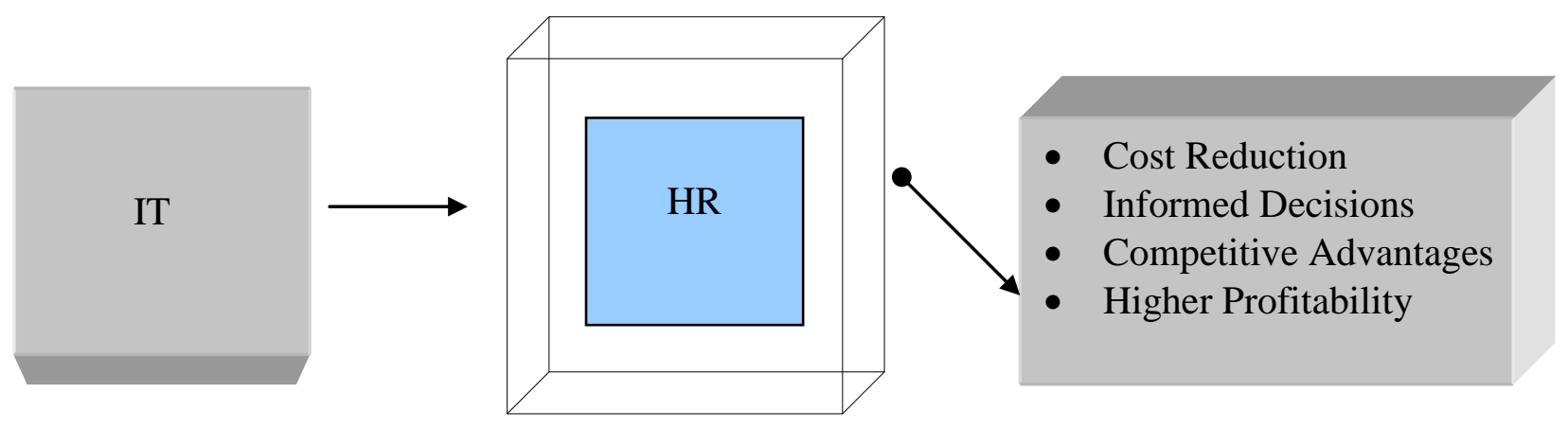

To fully understand the value of IT in HR, the major clusters of HR are defined with the intended outputs of each cluster, and IT's potential role in realizing the intended outputs of the respective HR clusters. Given the increasing use of technology in the workplace, Ulrich (2000) highlighted that HR departments must adapt Webbased systems in two major areas (p. 14).

First, transaction activities in HR shifted in the 1990s from business units to service centers. This is where HR departments created 1-800 numbers for employees to use to seek answers to their questions and make basic requests. The next step according to Ulrich (2000) is to put the service centers online and build employee selfservice, or self-reliance. The potential benefits include the traditional HR administrative tasks such as payroll processing, benefits administration, stock plan management, and other administrative tasks being done online at the employees' convenience, reduced labor costs, and generally a more efficient process and less expenses.

The second area according to Ulrich (2000) is the shift of transformational work of HR to the Web. The need to transform traditional methods of conducting strategic planning, training and development, employee selection, knowledge management, organization change and development, structuring organizations, compensation administration, organization communication, and other facets of HR activities to a Web-based system is crucial to the growth, effectiveness, and even the survival of the HR function.

\section{Strategic Planning}

The role of the HR function has changed tremendously over the past 10 years where HR functions have previously been viewed as not being an integral core of the business and merely viewed as an administrative function to today's economy where HR practitioners are more frequently considered business partners (Ramlall, 2003). Being a business partner, the ideal situation would be the inclusion of the HR leader in the strategic business planning (SBP). "In the most fundamental sense, SBP involves choosing how an organization will compete" (Rothwell, 1994).

Strategic HR planning involves the process of how HR will be part of the business strategy to create value for the organization. Critical issues discussed at this process, include how HR will compete, what strategies have been successful in the past, analysis of the internal and external environments, competitors, gap analysis of the organization and the workforce, reviewing customer and other stakeholder needs and demands, and other similar factors contributing to an organization's success.

How can IT enhance the effectiveness of strategic HR planning? In choosing how an organization will compete and HR's role in this mission, there are numerous ways in which value can be created and enhanced through collaboration between HR and IT. First, HR has to determine if there is adequate expertise currently within the organization to create the necessary value. Second, is the organization using the appropriate technology to 
deliver the services and products to the customers? Third, is there a need to make any planned organizational change based on the decision of how the organization will compete? Based on a detailed gap analysis, is there a need to invest in new technology and how prepared is the workforce to use the new technology?

With these critical questions, there is a clear need for top level discussions between leaders in HR and IT in order to fully leverage competencies, skills, and expertise within an organization. Furthermore, this collaboration at the strategic planning process would ensure that a) the available technology is appropriate in delivering the products and services to the customers, b) the employees have the appropriate expertise to maximize the technology, c) employees are actually using the technology available, and d) HR and IT partner to assess the effectiveness in creating value for the organization.

\section{Employee Selection}

As reflected in the SHRM (2002) study, technology is a top trend within the HR profession. In particular, online recruiting is ranked as one of the most important issues for HR in the future. As one of the most critical elements of the employment process, technology plays a crucial role in advertising, recruiting, and selecting employees who most fit with the organization and its needs. Historically, firms have used the newspapers, colleges and university career services, and employee referrals to advertise open positions.

Even in slower economic times, the argument can still be made about the need to attract the type of candidates who will create and sustain competitive advantages over a relatively long period of time. In today's global economy, recruitment is not limited to the particular geographic region in which one operates. Rather, companies have the luxury, through available technology, to advertise an open position across the world for a relatively low cost. It should be noted that the scope to which one advertises would obviously depend on the type of position, compensation, etc.

Anecdotal evidence suggests that the most successful companies in the world have not only created multinational corporations, but have created workforces and corporate cultures that reflect the characteristics of the global markets in which they operate (Kahn, 1998). These companies, including General Electric, Coca-Cola, Microsoft, Walt Disney, Intel, Toyota Motors, and Hewlett-Packard, believe that employees are the key to their respective success. Extensive employee selection processes is one of the efforts in which these companies utilize to recruit and select the applicant that is most suited for the position.

The growth of the Web has opened up new vistas for recruiting efforts in organizations. A 2001 survey of HR executives indicated that electronic boards were the most effective source of recruits for $36 \%$ of the respondents, with $21 \%$ for newspapers, $4 \%$ for job fairs, and $1 \%$ for walk-ins and referrals (Smith, 2001). Ways in which technology can be used for recruiting purposes include a) a company's own web page, b) interact with large, well known websites such as monster.com, hotjobs.com, etc., c) niche boards, d) video conferencing allows for interaction without having to travel (Noe, Hollenbeck, Gerhart, \& Wright, 2003). Utilizing these sources provide a direct reduction in costs, with faster "turnaround cycles," reduced opportunity costs, and increasing the organization's probability of the preferred candidate accepting the job offer.

\section{Employee Training \& Development}

Swanson (1995) defined employee training and development as the process of systematically developing expertise in individuals for the purpose of improving performance. The Internet and Web-based technologies have affected formal learning in the workplace and contributed to improving workplace performance (Lee, Owens, \& Benson, 2002). The American Society for Training \& Development [ASTD] (2002) pointed out that although faceto-face, instructor-led training exceeds Web-based training today, the growth in Web-based training continues.

Gone are the days when it was always necessary for trainers to travel to training sites. The economic benefits of using technology to conduct training include a reduction in air travel, hotel accommodations, opportunity costs and other indirect costs. The other benefits of using Web-enhanced training and the Internet include an 
employee participating in the learning at anytime and able to pace oneself. It is also a medium used in developing expertise that is more flexible than the traditional method including a just-in-time approach to deliver the training.

Delivering a training program through various sources of technology is especially important as more than $85 \%$ of the jobs in the United States and Europe will require extensive use of knowledge (Noe et al., 2003). Integrating Web-based and Internet mediums for developing expertise is part of the real world today and becoming more necessary in the global economy.

\section{Knowledge Management}

Today's knowledge management systems integrate real-time information sharing and coordination between various departments, knowledge sharing and discussion between various departments, knowledge sharing and discussion between individual employees and teams, skill databases, company yellow pages, product and service information, and Web presence for customer information gathering (Tiwana, 2001). Forms of contemporary knowledge management technologies include intranets and extranets, virtual community collaboration tools, data warehousing, mining, and analysis tools, web-based intelligence systems, and automatic tools for generating new knowledge (Ardichvili, 2002).

These advancements in technology enable organizations to capture and disseminate information to the applicable parts of the organization in order to create products and deliver services that meet and exceed customers' expectations and perform better than the competitors. The outcomes have been part of HR's responsibility historically. What is different is that HR has its reach, many forms of technology that would more efficiently and accurately perform these tasks as a means of differentiating itself from the competitors.

These strategies are especially important given that up to $75 \%$ of the source of value in a company is intangible intellectual capital (Zimmerman, 2001) resulting in the creation of competitive advantages for the organization. Again, the partnership between HR and IT can be of significant value and potential for creating sustained competitive advantages for the organization.

\section{Organization Change and Development}

Organization development (OD) is a data-driven process for change, and as a result, the successful application of OD interventions and tools has become increasingly dependent on the use of IT (Church, Gilbert, Oliver, Paquet, \& Surface, 2002). It may be instrumental in OD interventions such as targeted development aimed at senior leaders or other managers, enhancing quality initiatives, self-directed learning, career development, and instant employee opinion surveys.

Cummings \& Worley (2001) firmly stated that OD must adopt its methods to the technologies being used in organizations. Furthermore, as IT continues to influence organization environments, strategies, and structures, OD will need to manage change processes using the Web as well as face-to-face.

In addition, using a quantitative approach and integrating the available technology, there is a greater tendency for employees to support the planned change and work towards the intended outcomes of the change effort. This is in sharp contrast to the "touchy feeling" approach that has been synonymous to OD historically.

\section{Organization Structure}

What is the importance of an organization's structure in enabling technological changes? First, organization structure can be simply defined as the formal reporting relationships, grouping of employees, and systems within an organization. Daft (2001) stated that organizations are faced with the challenge of creating both organic and mechanistic conditions to achieve both innovation and efficiency. He suggested using the "ambidextrous" approach. This is where organizations are incorporating structures and management processes that are appropriate to both the creation and use of innovation and efficiency. 
It is of paramount importance to ensure that an organization's structure is designed in a manner that supports the creation of new ideas and maximize the use of available technology. Of what value is an investment in technology when employees are not empowered to utilize the technology to make business decisions? In today's global economy, an organic structure promotes the creation of new ideas within organizations, enables departments, through horizontal linkages within an organization to communicate and collaborate at a higher level of efficiency, enables sharing of information with suppliers and manufacturers, and allows employees to make decisions faster and more accurate.

By eliminating the barriers of organization communication, sharing of information and resources, and leveraging strengths, an organization has the potential to reduce expenses by making more informed decisions, avoid duplicating processes, and avoid competing with each other for the same resources. Technology is an integral strategy to ensuring that there is a balance between innovation and efficiency in any given organization. Due to HR being a hub of the organization and mostly responsible to designing organizational structures, the relation between HR and IT in designing an organization again shows the importance for full collaboration between the two functions.

\section{Compensation Administration}

In order to stay competitive, organizations are continually searching for ways to make faster and more accurate decisions. Compensation administration is no exception. For instance, classification and compensation analysts utilize market data to set pay at a competitive level that will attract and retain a workforce with the requisite skills. A common example of utilizing IT in compensation is the use of compensation administration software.

Compensation administration software integrates compensation management, job evaluation, pay structure, salary surveys, salary planning, electronic market pricing, incentive compensation, single or tiered performance measures, team and individual recognition, and job description and job evaluation modules. Standard and usercustomizable reports are often available (Frazee, 1996).

Furthermore, IT sources can often be used to capture data on employees' preferences for how they will be rewarded, satisfaction with current forms of rewards and therefore enabling organizational leaders to make more informed decisions. The availability of compensation through the use of technology also enables line managers to view, change when necessary and appropriate, and participate meaningfully in the compensation administration of their respective employees. Also, HR professionals and line managers are able to utilize the technology to generate reports for managing the workforce and making appropriate changes.

\section{Organization Communication}

Ulrich (2000) stated that Web-based firms have information ubiquity. Today's organizations demand that employees have ready access to information to make accurate and timely business decisions. Furthermore, anecdotal evidences indicate that employees appreciate and are expecting to be informed of any significant organizational issues, changes in policies, and developments affecting the organization.

Technology could also be used, through chat rooms, e-mail, video-conferencing, intranets, etc. managers, supervisors, and executives can communicate at any given time rather than to rely on the traditional sources of communication. For example, employees may view a company policy at any time if it is available on the intranet. These options are flexible and save a tremendous amount of time for employees.

What is HR's role in facilitating the use of technology to enhance communication in the organization? The benefits of communication are fairly obvious. As a function that connects and partners with the entire organization, $\mathrm{HR}$ is able to advocate the use of technology for improving communication. Second, since not all of the employees would be competent in using the various forms of technology, HR would have to ensure that employees are trained and have the necessary expertise in using the various forms of technology to communicate. Third, to encourage the use of technology to enhance communication and decision-making, the rewards systems could be developed to 
reflect such strategy. Fourth, the organization culture should reflect this paradigm. It should be only an espoused value, but one that is enacted.

\section{Summary}

With the increased need for IT in HR and an urgent need to reduce costs in organizations, one may be tempted to wonder about the possibility of replacing a few, some, or all of the traditional HR activities through wider use of IT and automation. Although this thought might be entertained by a few, by no means does collaboration mean replacement. There is clearly an urgent need for intense collaboration between HR and IT especially given the significant investments placed separately in labor cost and IT.

By understanding the relation between HR and IT, both functions are more able to develop and implement strategies leveraging each other to create value for the organization. A workforce with the appropriate technology and the competence to maximize any available technology, self-efficacy for learning and using new technology, and combining HR and IT expertise to create value for an organization provides a notion of comfort for creating and sustaining competitive advantages. The strategy of collaboration between HR and IT maximizes human capital and leverages investments in IT to ensure customers' demands are being met and in the most efficient manner.

CRamlall 2003

\section{References}

1. Afuah, A., \& Tucci, C. (2003). Internet Business Models and Strategies (Second ed.). Boston, MA: McGraw Hill.

2. Ardichvili, A. (2002). Knowledge Management, Human Resource Development, and Internet Technology. Advances in Human Resource Development, 4(4).

3. ASTD. (2002). State of the industry report. Alexandria, VA: American Society for Training \& Development.

4. Avgerou, C. (2000). IT and organizational change: An institutionalist perspective. Information Technology and People, 13.

5. Bacharach, S. B. (1989). Organizational theories: Some criteria for evaluation. The Academy of Management Review, 14(4), 496-515.

6. Benson, A., Johnson, S., \& Kuchinke, K. P. (2002). The Use of Technology in the Digital Workplace: A Framework for Human Resource Development. Advances in Human Resource Development, 4(4).

7. Boudreau, J., \& Ramstad, P. (2002). From "Professional Business Partner" to "Strategic Talent Leader": "What's Next" for Human Resource Management. Ithaca: CAHRS/Cornell University.

8. Canzer, B. (2003). e-Business: Strategic Thinking \& Practice. Boston, MA: Houghton Mifflin Company.

9. Cascio, W. (2003). Managing Human Resources: Productivity, Quality of Work Life, Profits (6th ed.). New York: McGraw-Hill Education.

10. Church, A., Gilbert, M., Oliver, D., Paquet, K., \& Surface, C. (2002). The Role of Technology in Organization development and Change. Advances in Human Resource Development, 4(4).

11. Coates, J. F. (2001). HR in an era of new strategic opportunities. (human resources). Employment Relations Today, 28(2).

12. Cummings, T., \& Worley, C. (2001). Organization Development and Change. Mason, Ohio: SouthWestern College Publishing.

13. Daft, R. (2001). Prganization Theory and Design (Seventh ed.). Cincinnati: South-Western College Publishing.

14. DeFillippi, R. J. (2002). Organizational Models for Collaboration in the New Economy. Human Resource Planning, 40(2).

15. Department-of-Commerce. (2002). A nation online. How Americans are expanding their use of Internet: Department of Commerce, National Telecommunications and Information Administration website.

16. Devaraj, S., \& Kohli, R. (2000). Information technology payoff in the health care industry: A longitudinal study. Journal of Management Information Systems, 16. 
17. Dubin, R. (1978). Theory Building (revised edition). New York: Free Press.

18. Frazee, V. (1996). Software automates standard HR processes. Personnel Journal, 75(11).

19. Huselid, M. (1995). The Impact of Human Resource Management Practices on Turnover, Productivity, and Corporate Financial Performance. Academy of Management Journal, 38.

20. Kahn, J. (1998). The World's Most Admired Companies. Fortune.

21. Kelly, K. (1998). New Rules for the New Economy. New York: penguin Putnam.

22. Lawler, E. E., \& Mohrman., S. A. (2000). Beyond the Vision: What Makes HR Effective? Human Resource Planning, 23(4).

23. Lee, W., Owens, D., \& Benson, A. (2002). Design Considerations for Web-Based Learning Systems. Advances in Human Resource Development, 4(4).

24. Lynham, S. (2000). Theory Building in the Human Resource Development Profession. Human Resource Development Quarterly, 11(2).

25. Noe, R., Hollenbeck, J., Gerhart, B., \& Wright, P. (2003). Human Resource Management: Gaining a Competitive Advantage (Fourth ed.). NY: McGraw Hill.

26. Patel, D. (2002). What's ahead for HR? SHRM research identifies top trends: Society for Human Resource Management.

27. Patra, R. K., Khatik, S. K., \& Kodwani, A. D. (2002). Human resources professionals at the crossroads. International Journal of Human Resources Development and Management, 2(3/4).

28. Ramlall, S. (2003). Measuring Human Resource Management's Effectiveness in Improving Performance. Human Resource Planning, 26(1).

29. Rothwell, W. J. (1994). The Background and Purpose of HRD. Human Resource Development Quarterly, 45 .

30. Smith, J. (2001). Is Online Recruiting Getting Easier? Workforce, 25.

31. Svoboda, M., \& Schroder, S. (2001). Transforming human resources in the new economy: developing the next generation of global HR managers at Deutsche Bank. Human Resource Management, 40.

32. Swanson, R. (1995). The Purpose of HRD: Performance is the Key. Human Resource Development Quarterly.

33. Tiwana, A. (2001). The essential guide to knowledge management. NJ: Prentice Hall.

34. Toracco, R. J. (1997). Theory-building research methods. Linking research \& practice. San Francisco: Berrett-Koehler.

35. Ulrich, D. (2000). From eBusiness to eHR. Human Resource Planning, 23(2).

36. Ulrich, D. (2001). From Partners to Players: Extending the HR Playing Field. Human Resource Management, 40(4), 293-307.

37. Viere, C. (2003). Partnering to Improve Performance: Linking Human Performance and Information Technology to HRD. Paper presented at the Academy of HRD, Minneapolis, MN.

38. Zimmerman, E. (2001). What are employees worth? Workforce, 32-36. 